\title{
Sturge-Weber syndrome diagnosed in a 45-year-old man
}

\begin{abstract}
A 45-year-old man with diaA betes mellitus and extensive congenital port-wine stains on the right side of his face (Fig. 1) had an upper respiratory tract infection for 1 week. He developed bilateral blurred vision and hyperglycemia and was admitted to hospital. Over the next week he experienced visual distortions, decreased visual acuity bilaterally, left homonymous hemianopsia, disconjugate gaze, ataxia and persistent confusion, and he then had a generalized seizure. He had no prior history of seizures, visual problems or poor school performance. His CT scan and MRI (Fig. 2) ref vealed mild focal encephalomalacia in the right occipital lobe with overlying leptomeningeal "ृ. enhancement (A) and ipsilateral choroid plexus thickening and enhancement (B) consistent with Sturge-Weber syndrome. $\AA$ An electroencephalogram dis-
\end{abstract}
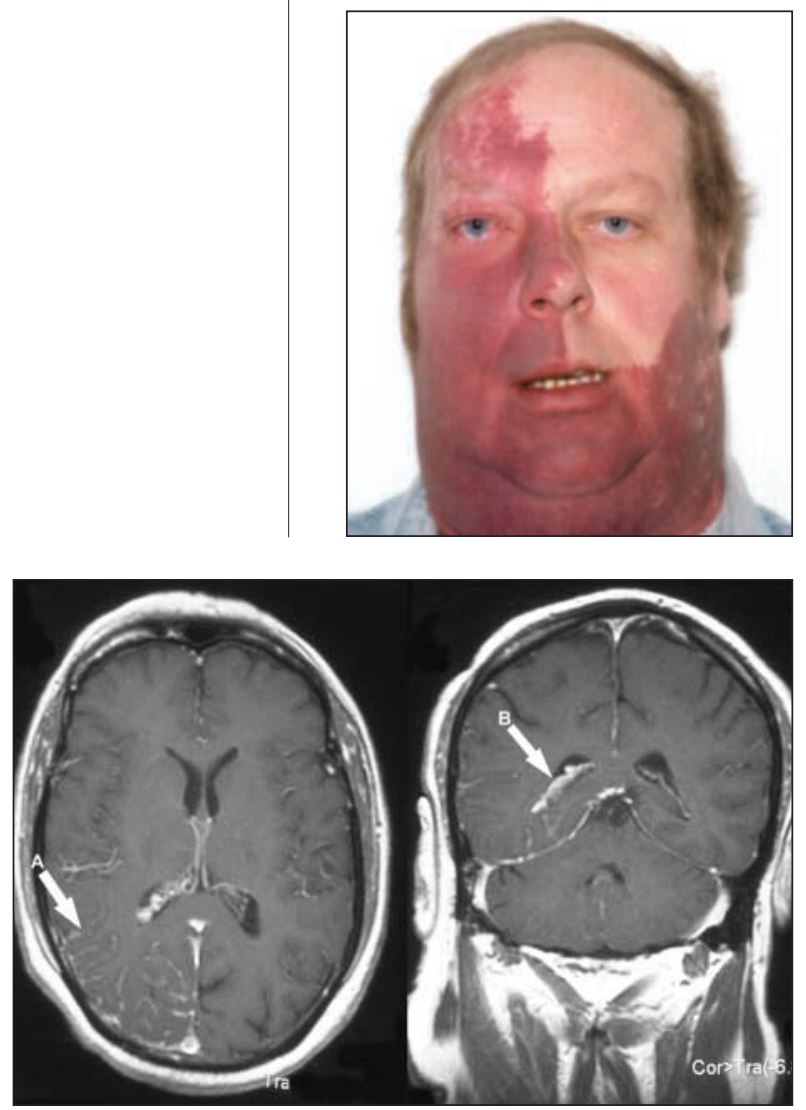

played generalized paroxysmal sharp- and slow-wave activity bilaterally, greater on the right side. Neuro-ophthalmological examination revealed a left homonymous hemianopsia, farsightedness in the left eye and an increased cup-to-disc ratio indicating chronic open-angle glaucoma in the right eye. He was given timolol eye drops in his right eye, glasses for his farsightedness and phenytoin. $\mathrm{He}$ had no further seizures and was discharged home. At follow-up 3 months later, his left homonymous hemianopsia had resolved.

Sturge-Weber syndrome is a neurocutaneous syndrome consisting of a port-wine nevus in the distribution of the ophthalmic branch of the trigeminal nerve (V1) and central nervous system malformations. Seizures and neurological deterioration typically develop in the first year of life ${ }^{1}$ rather than in adulthood and rarely after the third decade. The syndrome results from malformation of the cerebral vasculature located within the pia mater, most commonly over the occipital region. ${ }^{2}$ These malformations lead to venous hypertension and subsequent hypoperfusion of the underlying cortex, causing chronic cerebral ischemia, atrophy and neurological deterioration. ${ }^{1}$ Seizures are controlled with antiepileptic medications in $40 \%$ of affected patients. ${ }^{3}$ Cortical resection of the affected brain areas is sometimes advocated in cases of seizures uncontrollable by medication, but some favour surgery before permanent neurological deficits can develop. ${ }^{4}$

Only port-wine stains in the $\mathrm{V} 1$ distribution have been shown to be associated with leptomeningeal angiomatosis, which defines Sturge-Weber syndrome. ${ }^{1}$ Enjolras and associates $^{5}$ reviewed 42 cases of port- wine stains in the $\mathrm{V} 1$ distribution and found that patients were at increased risk when the entire V1 distribution was covered, with $11(44 \%)$ of the 25 such patients having SturgeWeber syndrome. Seventeen patients had part of the V1 distribution covered by a port-wine nevus; only 1 was found to have the syndrome. Ophthalmic abnormalities are most common in individuals with both V1 and V2 (maxillary division of the trigeminal nerve) involvement. Glaucoma occurs in 30\% of patients with Sturge-Weber syndrome, and it develops before 2 years of age in $60 \%$ of these patients. ${ }^{1}$ People of any age with port-wine stains in the V1 distribution may have Sturge-Weber syndrome and be at risk of seizures and neurological complications. They require yearly eye examinations and measurements of intraocular pressures, regardless of whether they have had symptoms in childhood.

\section{Muhammad S. Hussain}

Division of Neurology

Derek J. Emery

Department of Radiology

James R. Lewis

Department of Ophthalmology

Wendy S. Johnston

Division of Neurology

University of Alberta

Edmonton, Alta.

\section{References}

1. Paller AS. The Sturge-Weber syndrome. Pediatr Dermatol 1987;4(4) $300-4$.

2. Sadda SR, Miller NR, Tamargo R, Wityk R. Bilateral optic neuropathy associated with diffuse cerebral angiomatosis in Sturge-Weber syndrome. f Neuroophthalmol 2000;20(1):28-31.

3. Arzimanoglou A, Aicardi J. The epilepsy of Sturge-Weber syndrome: clinical features and treatment in 23 patients. Acta Neurol Scand Suppl 1992;140:18-22.

4. Arzimanoglou AA, Andermann F, Aicardi J, Sainte-Rose C, Beaulieu MA, Villemure JG, et al. Sturge-Weber syndrome: indications and results of surgery in 20 patients. Neurology 2000;55(10): 1472-9.

5. Enjolras O, Riche MC, Merland JJ. Facial port-wine stains and Sturge-Weber syndrome. Pediatrics 1985;76(1):48-51 